\title{
OSKRBNE FUNKCIJE V ORGANIZACIJI MESTNEGA PROSTORA - NA PRIMERU MARIBORA
}

\author{
Mirko Pak \\ Pod vrbami I, I000 Ljubljana, Slovenija \\ e-mail: mirko.pak@guest.arnes.si
}

Izvirni znanstveni članek

COBISS 1.01

\section{Izvleček}

Trgovina je eden najbolj dinamičnih, občutljivih in kompleksnih dejavnikov rabe in organizacije mestnega prostora. To so tudi osnovna vprašanja te študije regionalnega središča Maribora. Kot nosilci procesa stopajo v ospredje nakupovalna središča, ki odločilno vplivajo ne le na funkcijski, temveč tudi na splošni razvoj mestnega središča.

Ključne besede: trgovina, nakupovalna središča, razvoj, položaj, Maribor, Slovenija.

\section{SUPPLY FUNCTIONS IN THE ORGANISATION OF URBAN AREA - AN EXAMPLE OF MARIBOR}

\begin{abstract}
Trade is one of the most dynamic, sensitive and complex factor of use and organisation of urban areas. These are the basic questions discussed in this study about the regional centre of Maribor. Shooping centres are strengthening their role of holders of the procedure, having decisive influence not only on functional but also on overall development of town centre.
\end{abstract}

Key words: retail, schopping centres, development, spatial distribution, Maribor, Slovenia. 


\section{UVOD}

Procesi reurbanizacije, revitalizacije in suburbanizacije povsod po svetu spreminjajo rabo tal, ter fizično, funkcijsko in socialno zgradbo mest. Z investicijami podprta ekonomska ekspanzija v zadnjih letih udejanja vse zgoraj naštete procese hkrati, ki na ta način zajamejo ves mestni prostor od mestnih središč vključno z obmestji. Slednje Drozg označuje kot poligon za lociranje urbanih dejavnosti in tradicionalno seveda tudi nakupovalnih središč ${ }^{1}$ (Drozg, 1999). Procesa reurbanizacije in s tem povezane intenzifikacije sta ob liberalnejši urbanistični politiki na eni in rastočem potrošništvu na drugi strani, še posebej močno zajela mesta v nekdanjih socialističnih državah. Notranje razraščanje mest še posebej omogoča intenzifikacija ekstenzivno izrabljenih površin. Teh je v Mariboru veliko več kot na primer v Ljubljani. Pri tem gre za prestrukturiranje ekstenzivno izrabljenih in degradiranih površin, sanacijo, dograjevanje, širitev in zapolnjevanje prostih površin (Lobnik, 1999).

Odmik od prevladujoče proizvodnje k storitvenim dejavnostim, med katerimi oskrbna funkcija nedvomno izstopa tudi v vseh slovenskih mestih, je zaradi poudarjenega preteklega industrijskega značaja še posebej opazen v Mariboru. To prinaša znatne spremembe $\mathrm{v}$ rabo površin in $\mathrm{v}$ funkcijsko zgradbo mesta. Ob tradicionalni koncentraciji oskrbe $\mathrm{v}$ mestnih središčih in v redkih ustrezno opremljenih oskrbnih subcentrih, ki jih v Mariboru predstavljajo tudi lokalne trgovske ceste, je obdobju krepitve lokalne oskrbe v osemdesetih in devetdesetih letih prejšnjega stoletja, sledila predvsem gradnja novih oskrbnih središč na razpoložljivih mestnih lokacijah. Ekonomski vidiki tega procesa se manifestirajo v finančni realizaciji ter posredno $\mathrm{v}$ ceni in najemnini trgovskih površin in $\mathrm{v}$ spremembi namembnosti prostora. Posledica je manjšanje števila trgovin na eni ter večanje števila gostinskih lokalov, pisarn in nezasedenih prostorov na drugi strani, odviseno od vedno močnejše konkurence. Skupno število potrošnikov in njihova kupna moč ostajata $\mathrm{v}$ glavnem nespremenjena, ob tem pa se razraščajo marketi in nakupovalna središča. $\mathrm{V}$ tem razvoju prednjačijo velika nakupovalna središča, ki težijo tudi k nadaljnjemu razvoju. Večja in boljša ponudba, ki je vedno pogosteje dopolnjena tudi z drugimi oskrbnimi dejavnostmi in oblikami preživljanja prostega časa, primer za to je Planet Tuš, siromašita manjše trgovine, pa tudi lokalna in druga manjša nakupovalna središča. Lep primer je drastičen padec prometa v obstoječih velikih nakupovalnih središčih ob gradnji vedno večjih v Leipzigu, pa tudi gradnja novega nakupovalnega središča na južnem obrobju nam ne tako oddaljenega Gradca v Avstriji. Podoben razvoj doživljajo manjša nakupovalna središča iz devetdesetih let v Ljubljani Murgle center, Tabor in WTC, pa tudi okolica predela Ajdovščina in še kje (Pak, 2002). Podoben proces je zajel tudi manjše trgovine in markete $\mathrm{v}$ lokalnih središčih in v samem središču Maribora. Vsa nasprotna prizadevanja tako v Ljubljani kot v Mariboru takšen proces niso mogla zaustaviti, oziroma ustrezno preusmeriti. Raziskava trgovine v središču Ljubljane okrog leta 1990 je pokazala, da gre tukaj le za posamezne primere naseljevanja ustreznih dejavnosti, da to poteka skrajno počasi in je največkrat povezano s prenovo mestnega jedra. Takšen proces v prid velikih trgovin potrjujejo

\footnotetext{
1 V prispevku se uporabljajo termini: trgovina, nakupovalna središča, oskrba, oskrbna središča, kar je odvisno od samega značaja in od funkcije predmeta obravnave. Oskrba je vsebinsko širša opredelitev, kar velja tudi za mednarodno uveljavljena termina nakupovalno in oskrbno središče, na primer shopping center in, ali Einkaufszenter in Versorgungszenter.
} 
tudi podatki o tem, da se je v obdobju 1989/2001 število prodajaln v Mariboru povečalo le za $84,1 \%$, obseg prodajnih površin pa za $140,1 \%$ in povprečna velikost prodajalne od 142 na 192 m2 (Rebernik, Jakovčić, 2006).

Drozg ugotavlja, da imajo nakupovalna središča naslednje prednosti: boljšo dostopnost, koncentracijo različnih trgovin na majhnem prostoru, veliko izbiro blaga in dejavnosti, daljši obratovalni čas in niso odvisna od vremenskih razmer, postajajo pa tudi vedno bolj urbana vozlišča (Drozg, 2001). Glede na značaj naših nakupovalnih središč pa kot pomemben dejavnik izstopa tudi poraba časa pri nakupovanju (Rebernik, Jakovčić, 2006).

Raziskava trgovine v »trgovskem središču« Maribora in v nakupovalnih središčih, ki so jo opravili sodelavci Katedre za gospodarsko geografijo in regionalno planiranje Univerze v Bayreuthu je pokazala, da je nakupovanje odvisno predvsem od ponudbe, cene in splošne dostopnosti ter le v manjši meri od ambienta, ne pa tudi od prometne dosegljivosti. Zaradi višjih cen in slabše prometne dostopnosti mestno jedru $\mathrm{v}$ absolutnem in $\mathrm{v}$ relativnem pomenu izgublja. Med drugim je že leta 2000 večina anketiranih nad polovico svojih nakupov opravljalo v nakupovalnih središčih. To velja tudi za prostorsko sicer manj mobilno prebivalstvo v starosti nad 65 let (Maier, 2004).

Ekspanzija nakupovalnih središč vodi tudi v Mariboru k novemu vzorcu rabe in organizacije mestnega prostora, $\mathrm{k}$ spreminjanju njegove funkcijske zgradbe. V soodvisnosti s tem pa tudi k spreminjanju gostote pozidave, prometnega omrežja, socialne sestave posameznih mestnih predelov, vrednosti prostora in okolja ter mestno - obmestnih odnosov, oziroma suburbanizacije. V osnovi gre za novo organizacijo mestnega prostora na osnovi potrošnje namesto proizvodnje, ki je zamenjala stoletno odvisnost fizične, funkcijske in socialne zgradbe mesta od industrije. S tega vidika ima ta prispevek namen ovrednotiti nekatere prostorske posledice lokacije, razvoja in učinkovanja nakupovalnih središč, med katerimi po pomenu nedvomno izstopajo razvoj in lokacija nakupovalnih središč, njihova struktura in s tem povezana prometna problematika. Kaj nakupovalna središča kot vedno močnejše koncentracije potrošnje in že prava mestna vozlišča, neposredno in posredno prinašajo v prostorski razvoj mesta in njegovih posameznih predelov.

\section{GEOGRAFSKA PROUČEVANJA OSKRBNIH FUNKCIJ}

Podobno kot geografija po svetu, namenja tudi slovenska geografija zadnja leta vedno več pozornosti oskrbnim funkcijam, kot vedno pomembnejšemu dejavniku regionalnega in urbanega razvoja. Razumljivo je, da so v ospredju teh proučevanj nakupovalna središča ter oskrba in še posebej trgovska funkcija mestnih središč. Že sredi osemdesetih let prejšnjega stoletja je podrobno kartiranje središča Maribora pokazalo na začetke decentralizacije trgovske funkcije, pa tudi na razvojno zaostajanje tradicionalnih lokalnih oskrbnih predelov mesta ob Tržaški cesti, ob Limbuški cesti na Studencih in ob Cesti IV. divizije na Pobrežju. Takšen proces se je poglabljal zaradi odpiranja bolje opremljenih marketov ob večjih ali manjših lokalnih koncentracijah trgovin (Pak, 1987). Skoraj dvajset let kasneje, ko so se že pojavila nekatera nova nakupovalna središča, je podobna raziskava ugotovila, da center mesta izgublja in to predvsem zaradi višjih cen in slabše dostopnosti (Maier, 2001). 
Kar nekaj mednarodnih srečanj je bilo v zadnjih letih namenjenih izključno obravnavi novih oskrbnih središč, ki po svojem pomenu nedvomno izstopajo v razvoju mest. Še posebej je to v ospredju v nekdanjih socialističnih državah, kjer morajo zaradi razvojnega zaostajanja, probleme rabe mestnega prostora hitreje reševati. Večkrat je bila na takšnih srečanjih predstavljena tudi problematika slovenskih mest, zlasti podrobneje proučenih nakupovalnih središč »Murgle center«, »Tabor «, WTC in BTC v Ljubljani (Pak, 1996; Pak, 2001). Nadaljnje geografske raziskave so zajele predvsem večja nakupovalna središča v Ljubljani in v Mariboru ter generalno v Sloveniji (Drozg, 2001; Drozg, Pak, 2001a; Drozg, 2001b). Najbolj obsežno in metodološko poglobljeno primerjalno analizo BTC in mestnega središča $v$ Ljubljani pa je opravil F. Stare v svoji diplomski nalogi na Tehnični visoki šoli v Münchnu (Stare, 2004).

V svoji študiji kompleksne problematike nakupovalnih središč v Sloveniji je leta 2001 Drozg v 27 slovenskih naseljih opredelil 61 nakupovalnih središč. Razvrstil jih je glede na število trgovin $\mathrm{v}$ hipermarkete, velike specializirane trgovine, trgovske centre in trgovske komplekse; po velikosti jih je razvrstil v male, srednje in velike, po položaju v mestu pa na tiste v mestnem središču, na robu mestnega središča in na robu mesta (Drozg, 2001).

Po letu 2000 se je število nakupovalnih središč v Mariboru močno povečalo, večina obstoječih pa je bilo obnovljenih in če že niso povečali prodajnih površin, so jih vsaj vsebinsko obogatili. Večina jih je okrepila ali na novo pridobila določen položaj v oskrbnem omrežju mesta bodisi kot lokalno ter tudi kot oskrbno središče širšega mestnega ali celo regionalnega značaja. Postala so temeljni dejavnik ne le organizacije mestnega teritorija, temveč tudi njegovega razvoja. Večina oskrbnih središč, zlasti večjih, naj bi se strukturno okrepila in prostorsko razširila, tudi kot nosilec prostorskega razvoja mesta na sploh (Lobnik, 1999).

Pričujoča študija obravnava19 nakupovalnih središč v Mariboru, ki ob trgovski funkciji namenjenemu delu ožjega mestnega središča, ki je že bilo predmet dveh predhodnih študij in ob treh lokalnih trgovinskih koncentracijah ob cestah na Taboru, Studencih in na Pobrežju, izstopajo v funkcijski zgradbi mesta. Njihova opredelitev se opira sicer tudi na Drozgovo klasifikacijo nakupovalnih središč (Drozg, 2001). Vendar so določene razlike v izboru in kategorizaciji poslovnih središč predmet objektivno - subjektivne presoje tudi zaradi njihovega naglega razvoja $\mathrm{v}$ zadnjih letih. Vsekakor pa bi bilo ta pojav smiselno obravnavati v širšem kontekstu oskrbne funkcije. Saj bi lahko znaten del nakupovalnih središč imenovali tudi oskrbna središča (Versorgungszentren), kar velja še posebej za mestno jedro, stara lokalna, pa tudi za novejša nakupovalna središča, ki so ob krepitvi njihove trgovine vedno bolj tudi polifunkcionalna. Že omenjeni primeri manjših nakupovalnih središč v Ljubljani so pokazali nazadovanje trgovinske na račun drugih oskrbnih dejavnosti, še posebej poslovnih in gostinskih, pa tudi zdravstvenih. Za geografijo zanimiva in s praktičnega vidika koristna tovrstna problematika bo nedvomno tudi pogost predmet bodočih raziskav.

Pričujoča študija pa je osredotočena na sledeče »najbolj geografske« elemente problematike nakupovalnih središč ki so neposredno povezani z zgradbenim razvojem mesta:

- $\quad$ razvoj in razmestitev nakupovalnih središč,

- položaj in funkcija nakupovalnih središč v prostorski zgradbi mesta,

- oblika nakupovalnih središč,

- funkcijska zgradba nakupovalnih središč. 
- $\quad$ prometni položaj in pomen nakupovalnih središč $\mathrm{v}$ urbanem in regionalnem razvoju.

- $\quad$ izris pokrajinskoekoloških enot,

- $\quad$ končen izris meja pokrajinskoekoloških enot na topografski karti.

\section{ANALIZA NAKUPOVALNIH SREDIŠČ V MARIBORU - POLOŽAJ, RAZVOJ IN VELIKOST}

Maribor je izrazito dvojno mesto. Na levem bregu Drave prebiva le 1/3 in na desnem $2 / 3$ prebivalstva. Hkrati pa je večina oskrbnih funkcij in med temi posebej trgovin, še danes na levem bregu Drave. V sedemdesetih letih je bilo kar tri četrtine specializiranih prodajaln na levem bregu Drave, kamor je gravitiralo prebivalstvo vsega mesta (Pak, 1989). Staro mestno jedro v podaljšku do železniškega nasipa na vzhodu in na severu do Partizanske ceste, kjer je še vedno zgoščena oskrbna funkcija, doživlja zaradi rastočih cen zemljišč, nepremičnin in najemnin razpoložljivih površin, nazadovanja splošne urbane kvalitete in prometnih problemov ter zmanjšanja števila prebivalstva na njegovem obrobju, podobne razvojno - strukturne probleme kot druga mestna jedra. Tukaj se obdržijo predvsem visoko specializirane trgovine, ki lahko vzdržijo konkurenco zunanje specializacije (Maier, 2001 a). Tudi kvantitativna in predvsem kvalitativna širitev mestnega trgovskega središča preko dravskega mostu na desni breg Drave, na območje Trga revolucije, v sedemdesetih in osemdesetih letih, staremu mestnemu jedru ni prinesla pričakovanih rezultatov. Zato je bilo za ohranitev njegove trgovske funkcije leta 1997 na levem bregu Drave zgrajeno nakupovalno središče City, v nadaljevanju te osi v neposredni bližini preko Drave pa leta 2000 Europark z več kot $25000 \mathrm{~m}^{2}$ prodajnih površin. $^{2}$

Zaradi ugodnejših ekonomskih, prostorskih in prometnih pogojev, pa tudi populacijskih težišč, trgovska središča odpirajo na obrobju mestnih središč, mest, v predmestjih in v obmestjih, kjer je to tudi največkrat sestavni del živahne suburbanizacije. Do sredine devetdesetih let so bile v Mariboru ob mestnem središču na obeh bregovih Drave in ob že navedenih treh lokalnih oskrbnih cestah le še štiri tolikšne zgostitve oskrbnih dejavnosti, da jih je bilo mogoče opredeliti za znatnejša lokalna nakupovalna, oziroma v širšem pomenu oskrbna središča. Z izjemo takratnega marketa Kovinotehne ob Ptujski cesti so to bila vse lokalna oskrbna središča novih ali že obstoječih zgostitev prebivalstva. Vsa so ležala na desnem bregu Drave, dovolj oddaljena od mestnega središča in od treh lokalnih oskrbnih cest: na Pobrežju Greenwich, na Teznem med Prvomajsko in Ptujsko cesto in v naselju Maribor- Jug na Taboru. Razen mestni oskrbi namenjenega specializiranega marketa Kovinotehne, so bila preostala tri središča opremljena predvsem s trgovinami za kratkoročno oskrbo prebivalstva lokalnega vplivnega območja.

Za leto 2001 je Drozg na osnovi velikih trgovin »marketov« opredelil v Mariboru 12 nakupovalnih središč (Drozg, 2001). Leta 2006 pa je bilo na istem mestnem teritoriju opredeljenih 19 nakupovalnih središč, med katerimi so tudi vsa iz leta 2001. Število se je povečalo zaradi novih nakupovalnih središč in zato, ker so bila med nje štete tudi nekatere

2 Leta 2007 se bo Europark povečal na skoraj $40000 \mathrm{~m}^{2}$ prodajnih površin, na katerih bo 116 prodajaln in lokalov. 
večje koncentracije oskrbnih obratov. Nakupovalna središča so v glavnem sledila novim lokacijskim pogojem: razpoložljivi prostor, dostopnost in položaj v mestu. V zadnjih letih so bili razvojni trendi praviloma usmerjeni proti robu mesta, kar je povezano $\mathrm{z}$ gradnjo nakupovalnih središč širšega mestnega in regionalnega pomena. Ta ležijo večinoma ob glavni vpadnici z juga (Tržaški cesti), kjer so se, podobno kot v Ljubljani na Rudniku, naselile predvsem trgovine za dolgoročno oskrbo ter druge storitvene dejavnosti (Karta 1).

Karta 1: Nakupovalna središča 2006

Map 1: Shopping centres 2006

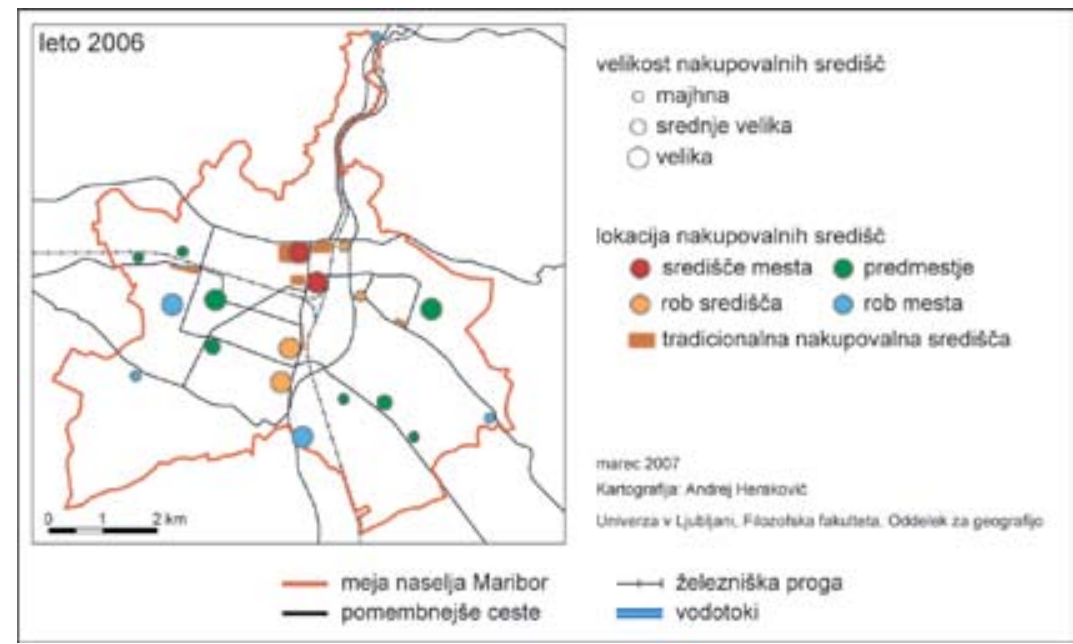

Druge lokacije velikih nakupovalnih središč so omogočile degradirane ali redko pozidane površine v delavskih predmestjih na desnem bregu Drave, kjer so tudi prostorske možnosti za njihovo širitev; Europarka proti jugu in najnovejših nakupovalnih središč Planet Tuš in Interspar na Studencih. Skupaj z nekoliko starejšim suburbanim nakupovalnim središčem ob železnici v Hočah je na ta način verjetno oblikovano osnovno in lokacijsko ustrezno omrežje velikih nakupovalnih središč za potrebe mestnega in okoliškega, pa tudi prebivalstva širše regije.

V drugo skupino spadajo manjša lokalna nakupovalna središča, ki so razen dveh specializiranih Merkurjevih marketov ob Ptujski cesti na Teznem in ob Sokolski cesti na Studencih vsa namenjena zadovoljevanju oskrbnih potreb lokalnega prebivalstva. Zato ležijo vsa ta nakupovalna središča z izjemo marketov Hofer ob Šentiljski cesti in Gigasport v Melju, v starejših ali novih stanovanjskih soseskah in so namenjena oskrbi lokalnega prebivalstva. Njihov hitrejši razvoj močno zavirajo velika nakupovalna središča, v katerih se to prebivalstvo redno oskrbuje. Tako se $\mathrm{v}$ teh središčih ohranja in le skromno tudi razvija trgovina za kratkoročno oskrbo, ki jo dopolnjujejo drugi obrati oskrbnega pomena, banke, pošte in podobno. Zato najdemo kar 7 od 9 tovrstnih središč v predmestjih in sta od teh le dve, središče Maribor-Jug ter ob Ptujski cesti na Teznem, pridobili značaj pravega mestnega oskrbnega subcentra. 


\section{OBLIKA IN STRUKTURA NAKUPOVALNIH SREDIŠČ}

Za slovenske potrebe je Drozg v svoji klasifikaciji nakupovalna središča uvrstil po številu trgovin v štiri skupine. Pri tem se pojem »nakupovalno središče« lahko različno uporablja vse od raznih marketov do zelo različno strukturiranega trgovinskega kompleksa (Drozg, 2001). V praksi pa gre še za bolj raznovrstno prepletanje trgovin in drugih oskrbnih obratov, odvisno od razvoja, velikosti, namena in še od česa. V Mariboru bi glede na velikost ali obliko nakupovalna središča razvrstili v tri skupine: velika nakupovalna središča pod eno streho, kjer izrazito prevladujejo trgovine, ki jih dopolnjujejo s trgovino povezani oskrbni obrati kot bančne izpostave in podobno, $\mathrm{z}$ gostinskimi obrati in $\mathrm{v}$ primeru nakupovalnega središča Planet Tuš tudi z zabavo. Tovrstna velika nakupovalna središča ponujajo čim bolj popolno trgovsko in s tem neposredno povezano ponudbo storitev, podobno kot sicer bistveno večja nakupovalna središča v velemestih. Ker pa obe največji mariborski nakupovalni središči City in Europark, velikih nakupovalnih središč v resnici ne dosegajo, gradijo nova podobna velika nakupovalna središča, v Mariboru na primer Planet Tuš in Interspar na Studencih ter Mercator Center na Pobrežju, ki so vsa zaživela koncem leta 2006. Vse analize BTC v Ljubljani so pokazale, da gradnja vedno večjih in bolje opremljenih nakupovalnih središč, ne da bi se hkrati povečalo tudi njihovo vplivno območje, močno zmanjšuje promet kupcev in blaga v že obstoječih, praviloma manjših nakupovalnih središčih. Gradnja novih nakupovalnih središč na robu Maribora bi zato močno prizadela že obstoječa, še posebej manjša nakupovalna središča. Primer za to je nakupovalno središče ob Borštnikovi ulici v Radvanju (Karta 2).

Karta 2: Oblike nakupovalnih središč leta 2006

Map 2: Forms of shopping centres in 2006

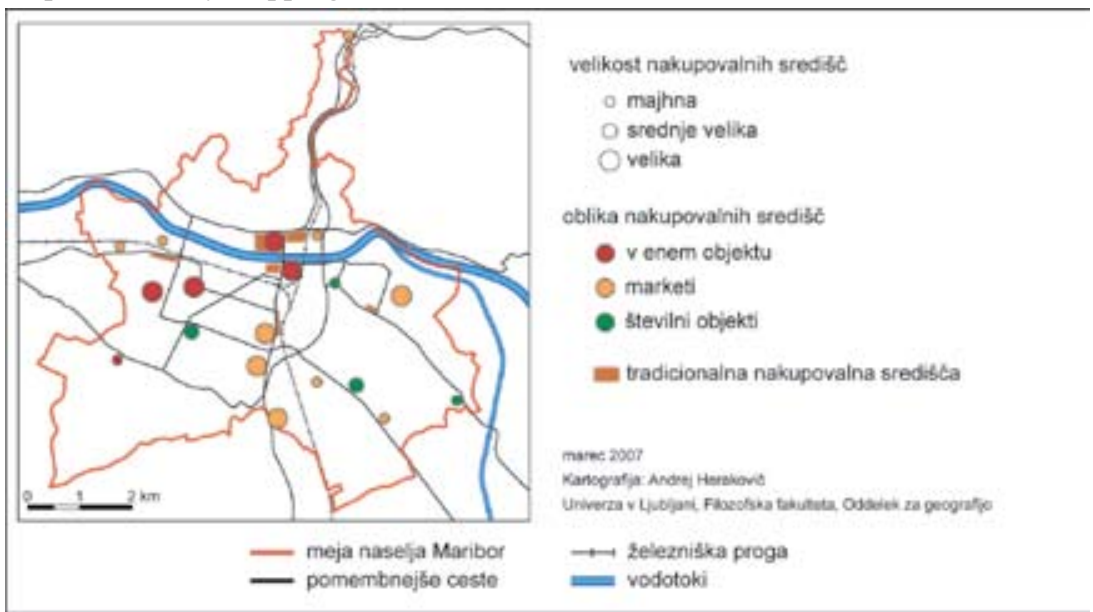

V drugo skupino lahko uvrstimo hipermarkete in specializirane trgovine, $v$ bistvu dve skupini trgovin. Posamezni marketi v stanovanjskih naseljih so namenjeni lokalni oskrbi, specializirani hipermarketi kot sta oba Mecatorjeva na Studencih in ob Ptujski cesti pa oskrbi 
prebivalstva vsega mesta. Ob križišču Tržaške, Ptujske in Ceste proletarskih brigad se je razvilo nakupovalno središče iz več hipermarketov in manjših trgovskih obratov, ki v praksi predstavlja funkcijsko nadaljevanje tradicionalnega trgovskega dela Tržaške ceste, podobno kot centra Ligro in Obi.

Lokalna trgovska središča praviloma sestavlja več trgovin in drugih oskrbnih obratov. Manjše tovrstne koncentracije (street corner), ki zapolnjujejo praznine v lokalni oskrbi so bolj številne in večje na desnem kot na levem bregu Drave kjer sledijo predvsem širjenju stanovanjskih predelov na obrobju mesta. Od tovrstnih koncentracij trgovin so bila $\mathrm{v}$ to obravnavo vključena nakupovalna središča ob Ptujski cesti, v naselju Maribor-Jug, na Pobrežju in v Brezju (Karta 3).

Karta 3: Funkcijska zgradba nakupovalnih središč 2006

Figure 3: Functional structure of shopping centres in 2006

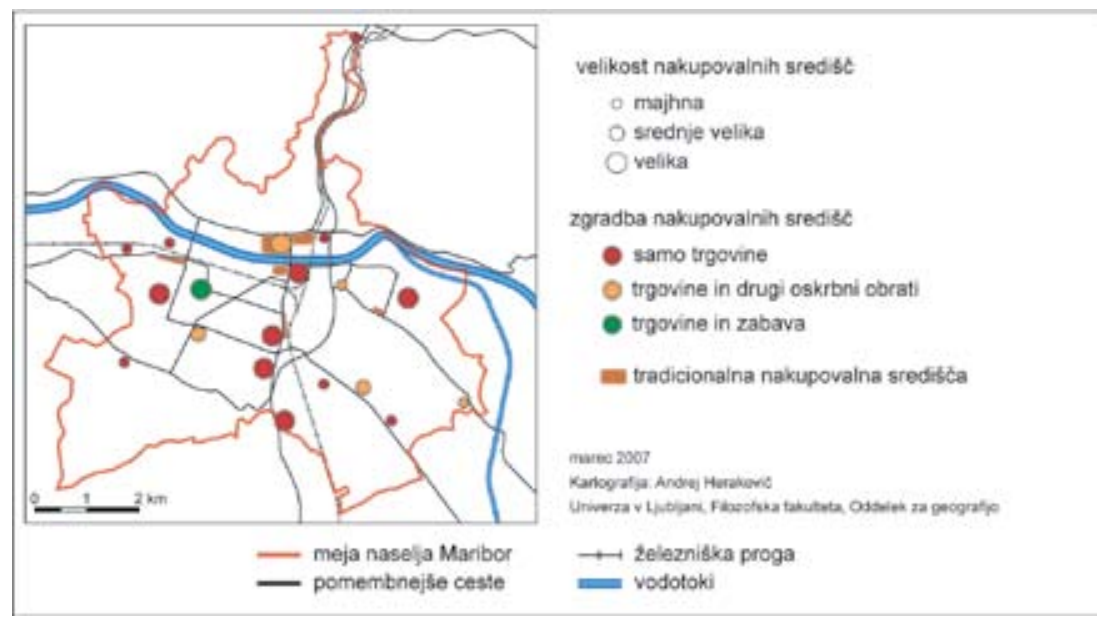

\section{PROMETNI POLOŽAJ}

Dobra prometna lega je skupni imenovalec vseh lokacij. Vsa večja nakupovalna središča v Sloveniji ležijo ob avtocestah, ob magistralnih cestah in ob mestnih vpadnicah (Drozg, 2001). Leta 1994 zgrajeno najstarejše nakupovalno središče v Zagrebu leži ob Starčevičevi ulici ob železniški postaji z zelo problematično prometno dostopnostjo (Lukić, Jakovčić, 2004). Podobne prometne probleme imajo tudi nekatera $v$ devetdesetih letih zgrajena nakupovalna središča v Budimpešti. Tudi 1997 leta odprto nakupovalno središče City v središču Maribora se otepa s problemi dostopa $\mathrm{z}$ avtomobili in parkiranja. Zanimivo pa je, da najstarejše nakupovalno središče na severnem robu Frankfurta »NW Einkaufzentrum«, ki je s cestno železnico in deželno cesto povezano z mestnim središčem, nikoli ni moglo zaživeti kot pomembnejše nakupovalno središče enega najbolj dinamičnih evropskih mest. Vse to kaže na silno prepletenost večjega števila dejavnikov, od katerih je, podobno kot drugod, tudi v 
Mariboru v ospredju dostopnost v širšem pomenu od samega klasičnega prometnega položaja (Karta 4).

Karta 4: Prometni položaj nakupovalnih središč leta 2006

Figure 4: Traffic position of shopping centres in 2006

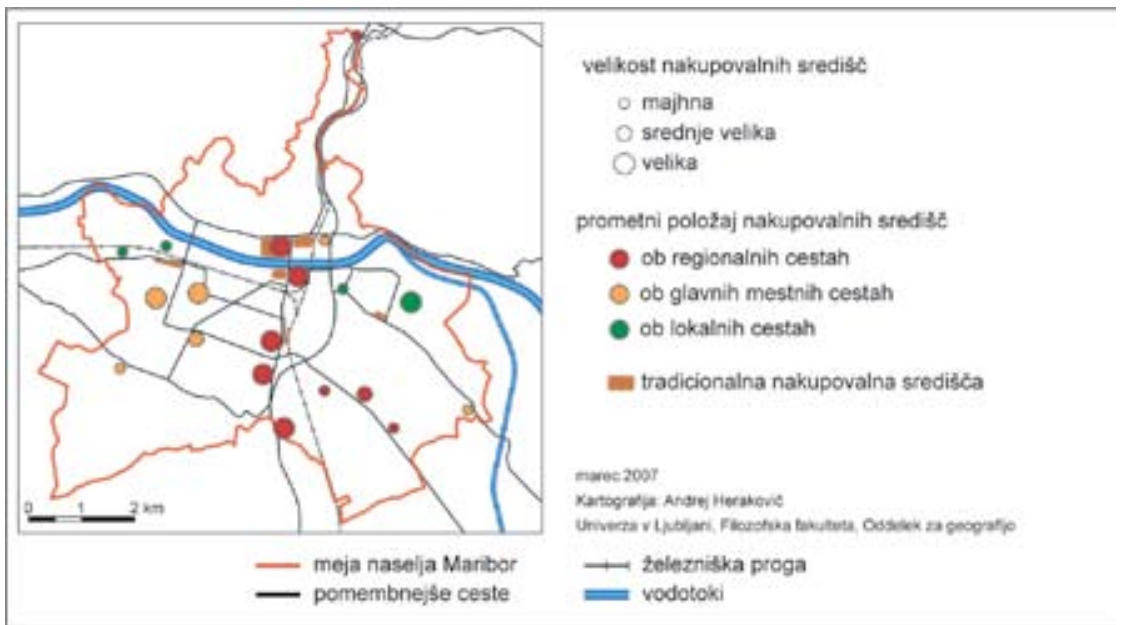

Vsa največja nakupovalna središča v Mariboru ležijo ob glavni mestni prometnici Titovi in v nadaljevanju ob Tržaški cesti. Tu ležijo City, Evropark, Mercator center, Legro, Obi na nekdanjem hipodromu in v podaljšku končajo s hočkim nakupovalnim središčem. Pri tem gre za izrazito povezanost med strukturo in prometnim položajem nakupovalnih središč, oziroma dostopnostjo. City center in Europark v mestnem središču sta brez prevoza dostopna prebivalstvu mestnega središča na levem bregu Drave, pri čemer je mestno središče zaradi svojega središčnega in prometnega položaja, tudi kot vozlišče javnega mestnega avtobusnega prometa, najhitreje dostopen mestni predel na sploh. Podoben prometni položaj ima Mercator center ob križišču Tržaške, Ptujske in Ulice proletarskih brigad, za prebivalstvo večjega dela desnega brega Drave. Ostala tri bolj oddaljena velika nakupovalna središča, ki so vezana na dostop z avtomobili, pa so namenjena pretežno srednje in dolgoročnim nakupom. Položaj ob osrednji mestni prometnici velikim nakupovalnim središčem ne zagotavlja le najboljši prometni položaj v okviru mesta samega, ampak tudi v regionalnem pogledu, kjer so še posebej prometno neposredno dostopni prebivalstvu gosto poseljenega Dravskega polja. Preostala večja nakupovalna središča so zaradi svojega položaja ob drugih glavnih mestnih cestah dobro dostopna prebivalstvu posameznih mestnih predelov; Planet Tuš na Poljanah, Interspar ob Studenški ulici in Tuš v Radvanju prebivalstvu Studencev, Tabora in podpohorskih naselij, preko Koroškega mostu pa tudi širšega mestnega središča na levem bregu Drave. Vsa ostala manjša lokalna nakupovalna središča večje soodvisnosti od prometnega položaja ne izkazujejo. 


\section{SKLEP}

V Mariboru je še posebej mogoče govoriti o neposredni soodvisnosti položaja in razvoja nakupovalnih središč od bližine potrošnikov. To potrjuje njihova lokacija v središču in na robu središča mesta, $v$ predmestjih in na mestnem robu. Zato je njihova ponudba zelo pestra, kar se z odpiranjem novih in širjenjem obstoječih nakupovalnih središče še stopnjuje. Sicer pa je trend podoben $v$ mestih vseh postsocialistčnih držav.

Optimalna položaja imata vsekakor Europark in Mercator Center ob Tržaški cesti, prvi ob stiku mestnih in regijskih prometnih tokov, drugi pa ob stiku treh glavnih treh mestnih predelov na desnem bregu Drave. Logično je zato nadaljnje širjenje oskrbne funkcije ob tej osi med Pobrežjem, Teznem in Taborom s Studenci vključno s starim trgovskim delom Tržaške ceste na robu mestnega središča. To je tudi območje znatnih nepozidanih, redko pozidanih in degradiranih površin. Zato se bo tu oblikovala novodobna mestna sredica, ki bo povezala štiri mesta v eno (Lobnik, 1999); tri predele na desnem in enega na levem bregu Drave.

$\mathrm{V}$ Mariboru se je v preteklosti trgovina razvijala izrazito centralistično $\mathrm{v}$ središču mesta, brez ustrezne oskrbnih subcentrov v obsežnih stanovanjskih predelih na desnem bregu Drave. Zato sta na primer najnovejši središči prvi ustrezno opremljeni nakupovalni središči na Poljanah in Studencih z delom Tabora, kjer se tudi omrežje marketov ni ustrezno razvilo. Ti rastejo v glavnem po letu 2000 skupaj z večjimi nakupovalnimi središči za potrebe vsakodnevne oskrbe lokalnega in za redkejšo oskrbo vsega mestnega prebivalstva.

Podobno kot v Ljubljani razvoj nakupovalnih središč tudi v Mariboru vpliva na degradacijo trgovine v mestnem središču (Stare, 2004; Maier, 2001a). To se neposredno kaže v skromnih investicijah v trgovino c središču mesta. Trgovina na Glavnem trgu ter na Koroški in Partizanski cesti kaže značilno podobo takšnega procesa, ki najprej prizadene robne predele središča. Trgovina se tudi v prejšnjih desetletjih ni uspela širiti na severni rob mestnega središča. In podoben proces doživlja tudi območje ob Trgu revolucije na desnem bregu Drave. V mestnem središču se sicer naselijo, podobno kot v Ljubljani, ozko specializirane trgovine, ob katerih vztrajajo stare trgovine, več je opuščenih lokalov, predvsem pa je vedno več prostora namenjenega gostinski in drugi netrgovinski dejavnosti. Stanje trgovine v mestnem središču je tako v Ljubljani kot v Mariboru soodvisno od prenove mestnega središča in še posebej mestnega jedra.

Gradnja novih in širjenje obstoječih nakupovalnih središč ni le ekonomsko vprašanje, ampak tudi vprašanje rabe in organizacije mestnega prostora. Sigurno zavira ustrezen razvoj drobne trgovine in lokalnih oskrbnih središč, spreminja pa mestne prometne tokove in v končni konsekvenci socialno zgradbo mesta. Ne nazadnje popolna polifunkcionalnost mestnega prostora, ki je sicer trend, tudi v svetu še ni dokazana za optimalen model rabe mestnega prostora.

\section{Viri in literatura}

Drozg, V., Pak, M., 1994. Zgradba mesta, Maribor/Marburg, prispevki h geografiji prijateljskih mest. Maribor. 45 -56.

Drozg, V., 1999. Obmestje, Maribor, Arhitektov bilten 39/julij. Maribor. 58 - 61. 
Drozg, V., 2001. Nakupovalna središča v Sloveniji, Geografski vestnik 73 -1. Ljubljana. 9-21. Drozg, V., Pak, M., 2001a. Einkaufszentren in Slowenien, Arbeitsmaterial ARL 282. Hannover. $187-102$.

Drozg, V., 2001b. Versuch der Bestimmung eines Entwicklungskonzepts von Einkaufszentren in Slowenien, Arbeitsmaterialien zur Raumordnung und Raumplanung 204. Bayreuth. $81-92$.

Lobnik, U., 1999. Značilnosti prostorskega razvoja urbane strukture, Maribor, Arhitektov bilten 39/julij. Maribor. $62-65$.

Lukić, A., Jakovčić, M., 2004. Location and function of hyppermarkets and shopping centers in Zagreb, Dela 22. Ljubljana. 39 - 54.

Maier, J., Menchen, N., Wöhler, L., 2001. Räumliche Muster des Einzelhandels in der Innenstadt und den Einkaufszentren am Innenstadtrand bzw. Aussenbereichen der Stadt Maribor, Arbeitsmaterialien zur Raumordnung und Raumplanung 204. Bayreuth. 93 - 103.

Maier,J.,Hessman.D.,2001a.EinzelhandelundneueEntwicklungenausderSichtderGeographie und Regionalforachung - Die neue Entwicklung der Einzelhandelsgrossprojekte in der MOE - Länder und der Vergleich zu den marktwirtschaftlich - kapitalistischen System, Arbeitsmaterialien zur Raumordnung und Raumplanung 204. Bayreuth. 1 - 14.

Pak, M., 1987. Nekateri elementi mestne zgradbe in ustroja mestnega središča Maribora, Časopis za zgodovinopisje in narodopisje 23 -1. Maribor. 3 - 20.

Pak, M., 1996. Problematika oskrbnih središč v Ljubljani, Nove smeri prostorskega razvoja. Maribor. $249-255$.

Pak, M., 2001. Raumordnungspolitischeund planungspolitische Behandlung des Einzelhandels in Slowenien, Arbeitsmaterialien ARL 282. Hannover. 183 - 185.

Pak, M., 2002. Funkcijska zgradba Ljubljane, Geografija Ljubljane. Ljubljana. 133 - 149.

Rebernik, D., Jakovčić, M., 2006. Development of retail and shopping centres in Ljubljana, Dela 26. 5 - 26.

Stare, F., 2004. Grosse Einkaufszentren am Staadtrand vs. innerstädtischen Geschäften in Ljubljana, Geografski vestnik 76 - 1. Ljubljana. 23 - 35 .

\section{SUPPLY FUNCTIONS IN THE ORGANISATION OF URBAN AREA - AN EXAMPLE OF MARIBOR}

\section{Summary}

Expansion of supply centres in the regional centre Maribor leads to a new model of use and organisation of the space. In the past, trade was concentrated in the narrower centre on the left bank of the river Drava, where 1/3 of all urban population used to live. However, trade on the right »industrial« bank of Drava with $2 / 3$ of the urban population was, as well as all supply activities, poorly developed. Three main trade roads served for the every-day supply in this area. To satisfy other supply needs, the population was oriented into the town centre.

In the seventies and eighties of the previous century, development of local centres was represented by the building of markets. Building of shopping centres which has expanded after 2000, resulted in significant changes in the supply infrastructure of the town. With the 
exception of the centre City in the town centre, all other centres are located on the right bank of Drava with uninhabited, degraded or sparsely inhabited surfaces. Of 19 recorder shopping centres, 5 are located in the centre of the town or on its outskirt, 9 in the suburbs and 5 on the outskirts of the town. Due to the under-developed supply infrastructure in the past, some of the new shopping centres have taken-over the function of supply centres for individual parts of the town on the right bank of Drava.

Available space, traffic situation and first of all accessibility are the basic location factors. This was why shopping centres concentrated along the main city road in the direction from the south to the town centre, with two locations pointing out. Shopping centres City and Europark, situated on both sides of Drava near the Drava bridge at the town-centre's outskirt, is accessible both from the high-road as well as without the car from the centre on the left Drava bank. Mercator centre together with a number of other markets and smaller stores at the crossroad of Tržaška and Ptujska road has thus the central position of the three main parts of the town on the right Drava bank. New shopping centres have been built in the last years also in residential suburbs. Most shopping centres have the tendency of spread. At the end of 2006 three new shopping centres were opened and one at the beginning of 2007.

Development of shopping centres affects stagnation or even regression of the trade in local supply centres, of small stores in general and, for more than ten years, also of the trade centre in the town. The reason is also closeness of such centres to consumers, who make use of them also for the every-day shopping. More than one half of consumers, which were questioned in the town centre, answered to do the majority of their shopping in the big shopping centres (Maier, 2994).

According to the urban design of Maribor, a town's supply centre is planned in the zone of the present concentration of shopping centres on the right bank of Drava. It is planned to be built on the empty and sparsely built-up surfaces on the juncture of four main town parts: town centre on the left bank, and Tezno, Pobrežje and Tabor with Studenci on the right bank of Drava (Lobnik, 1999). 